\title{
Drivindus Case Study: Choosing an e-Business Solution
}

\author{
Oihab Allal-Chérif \\ BEM Management School Bordeaux France, \\ 680 cours de la Libération 33400 Talence France \\ oihab@bem.edu
}

\begin{abstract}
Over time, Drivindus has become one of the world's leading manufacturers of automotive parts. This industrial group is present in 20 countries, employing 50,000 persons from 50 different nationalities and running around 100 factories and 40 research centers. It generates annual revenues of nearly $€ 10$ billion. The firm's General Management has noticed that productivity reserves still exist within its purchasing management function. The company has therefore decided to invest in an e-sourcing project. This case study describes this project which has been inspired from a real one and shows how an electronic marketplace has been designed to reach all the objectives. This case study takes between 4 and 6 hours to be solved by post graduate management students. They may be organized in groups of 4 and the instructor can go from one group to another to help them progress, according to their capacities, in answering the 5 questions. A PowerPoint presentation and teaching notes are provided to help in the animation of the case which has been tested and optimized in three different accredited management schools before its publication. It's ideal to illustrate purchasing management evolution and information systems management.
\end{abstract}

Keywords: Procurement function, Information Systems, e-business, project management.

\section{Presentation of the Company and the Purchasing Function}

The French group Drivindus is born out of the progressive merger of a number of smaller firms, some of which are at least 100 years old. Only French firms were involved at first, followed by European ones. Over time, Drivindus has become one of the world's leading manufacturers of automotive parts. This industrial group is present in 20 countries, employing 50,000 persons from 50 different nationalities and running around 100 factories and 40 research centres. It generates annual revenues of nearly $€ 10$ billion. The group organisation is a decentralised structure comprised of 10 branches (B1 to B10) corresponding to its commercial product lines. It has 15 main customers ( $\mathrm{C} 1$ to $\mathrm{C} 15)$. The organisation has evolved constantly to match customer demands. The group has a three-pronged structure, featuring an:

- Operational organisation shadowing each branch, materialising in divisions organised into autonomous profit centres. These are the key entities in the overall organisation and group several production sites specialised by product or system. 
- Functional organisation encompassing cross-departmental functions like financial control, human resources, legal services, product marketing, R\&D, quality and purchasing. These cross-departmental functions implement the group strategy. They develop and apply its methods and procedures; disseminate information; monitor the main investment projects; and supervise the realisation of objectives.

- Geographic organisation watching over group interests worldwide and managing relationships with automakers' headquarters.

Drivindus has always cooperated with its suppliers in the development of new components. This is a high-tech company where imagination and the invention play a considerable role in letting Drivindus partner its customers, who view the company as a valuable advisor and as a source of competitive advantage. The company's $€ 10$ billion in revenues are divided as follows: Europe: $70 \%$, North America: 18\%, Asia and Africa: $8 \%$, South America: 4\%. Sales growth has regularly been in double digits. The main explanation has been Drivindus's dynamism and acquisition of innovative smaller firms. The company operates in a very competitive sector but has succeeded in generating operational earnings of $€ 500$ million. R\&D spending equals $6 \%$ of sales, or an investment of more than $€ 600$ million.

Purchases amount to $60 \%$ of total turnover, or more than $€ 6$ billion. In other words, this is very strategic activity at Drivindus since it is both the basis of the company's cost structure and a key innovation driver. Saving $1 \%$ on purchasing costs corresponds in profitability terms to a $10 \%$ increase in sales. Purchasing is not only a major profit and innovation centre but also the department responsible for ensuring the quality of the components that Drivindus buys from its own suppliers, thus the quality of the sub-assemblies that it manufactures itself.

The Purchasing function has evolved thusly:

- Pre-1975: Purchasing was not yet considered a key function. Suppliers were not integrated into company operations but mainly chosen based on price. They had to compete intensively each and every time an order was renewed. All in all, this was a 'cost out' system characterised by limited and very short-term relationships.

- Between 1975 and 1985: The beginning of a delocalisation process that was a direct result of the group's very strong growth. Purchasing volumes rose considerably and total quality became more important than price alone. It was during this era that the company shifted from a 'cost out' to a 'value in' outlook.

- Between 1985 and 1995: The group started to internationalise and focus on innovation. Product life spans shortened, creating a need for partnerships with networks of highly innovative privileged suppliers, so as to foster and maintain competitive advantage. This was an era of long-term relationships, with Drivindus positioning itself as the leader of teams of suppliers working together.

- Since 1995, the group has been entirely geared towards global partnerships. This has led to an intense and systematic search for information, with Drivindus - together with its suppliers - constantly analysing the possibility of developing new products on a project basis. The notion of 'co-makers' has appeared.

Purchases can be broken down as follows:

- Natural and synthetic raw materials. The constraints in this market mainly involve localisation questions and speculation-driven price volatility. 
- Production components like electronic or mechanical parts. These are purchases from a range of very different markets, some of which are competitive and others more oligopolistic in nature. Prices are negotiated to varying degrees. Moreover, these purchasing segments require a great deal of strategic monitoring;

- Purchases relating to outsourcing contracts, like parts in complex systems requiring many exchanges of documents that can be voluminous and complex;

- General administrative (overhead) items like paper, office supplies or furniture. Suppliers rarely compete in these fields. Once chosen, they are asked to agree framework contracts specifying transaction conditions over a certain period of time;

- Purchases of services like maintenance (cleaning) or security, all of which are very localised. There are great disparities between the services offered in the different countries where Drivindus operates. Price differentials can also be significant;

- Logistics costs incurred when transporting goods;

- Engineering purchases, i.e. during the construction of a new plant;

- IT, including hardware, software and maintenance.

Drivindus has decided to cut costs by globalizing purchasing volumes. Suppliers can be categorised thusly:

- Local (often regional) suppliers who are usually quite small in size and work out of a single site. Volume effects are not possible with this kind of supplier;

- National suppliers with more extensive activities than local counterparts and greater responsiveness than international ones;

- International suppliers with whom the company can work in more than one country. These actors often possess a specific know-how that makes then indispensable. They transact enormous volumes, reducing the importance of any one customer;

- Low-cost suppliers with whom the company specifically works for this one reason. Turnover is quite rapid in this category, which presents quality and delivery risks.

\section{Description of the 'e-Business Project'}

The e-business project is very ambiguous and potentially headed in different directions, largely because it is driven by a variety of Drivindus managers, not all of whom have the same conceptions. Each views the project through the prism of very different realities. In short, Drivindus's e-business project has heterogeneous goals which makes it hard to find a global solution and explains why the project has had to be run over two phases. After appointing Mrs. Biz to manage the e-business project, Senior Management asked her to achieve the following objectives:

- Cut acquisition and procurement costs significantly (O1);

- Reduce the number of suppliers without endangering their autonomy, or indeed Drivindus's (O2). This is referred to as Purchasing globalisation;

- Homogenise the tender bid processes and the technical specifications communicated to suppliers worldwide (O3);

- Improve the company's general knowledge of its suppliers' competencies, means of production, financial structures or customer bases $(\mathrm{O} 4)$;

- Track supplier performance on both a day-to-day and global basis (O5); 
- Accelerate and raise the quality of dispute resolution mechanisms to solve any production incidents as quickly and efficiently as possible (O6);

- Help buyers leverage their knowledge and implement internal benchmarking (O7). Buyers must possess a tool that will allow them to engage in technological and strategic watch activities and share anything they learn with one another.

Senior Management is ready to invest in solutions that will give it a decisive competitive advantage by raising productivity and developing new partnerships with innovative suppliers.

Mrs. Biz has decided to call her e-business project E@SI, which stands for Ebusiness at Supplier Integration. As a concept, Supplier Integration is one of Drivindus's five strategic axes. The project is set to run over two phases: an initial stage mainly devoted to the standardisation, optimisation and globalisation of transactions and marked by significant cost-cutting efforts; and a second, more qualitative stage revolving around problems like the management of supplier relationships, establishment of new forms of collaboration, and leveraging of purchasing-specific knowledge and know-how. After exploring which tools and solutions are on offer in the e-business package markets or different electronic marketplaces, Mrs. Biz noted that none of them fully satisfies Drivindus's expressed needs and decided to initiate a series of sub-projects that she delegated to different project managers. Thus, it is not one but four e-business projects that will run concurrently, with a two-year gap between the transaction and cost phase versus the relationship and knowledge phase.

- The first sub-project (P1) involves online bidding and uses a reverse auction system for certain kinds of purchases. The project will run during phase 1 and start in 2006.

- The second sub-project (P2) involves web-procurement, i.e. purchases from standardised electronic catalogues. It runs during phase 1 and also starts in 2006.

- The third sub-project (P3), called SUMO for SUpplier MOnitoring, establishes a supplier referencing package. It will run during phase 1 and starts in early 2007.

- The fourth sub-project (P4) involves Supplier Relationship Management (SRM) and mainly manages quality disputes and supplier incidents through its Incident Management System (IMS) solution. This collaborative extranet project will run during phase 2 and start in 2008.

\section{Simplified Specifications}

Drivindus has very precise specifications for this first project. The tool must be simple and user-friendly yet provide very high value added. Reverse auctions have a mystique but also a relatively negative reputation. Many people have preconceptions about them, meaning that there is a strong possibility that Drivindus buyers could reject them. Drivindus considers it crucial that auctions do not deprive buyers of their role as negotiators and purchasers. Quite the contrary, the buyers' mission will become increasingly complex meaning that their workload will increase instead of being reduced. The goal is to gain time on tasks that generate little value added - and to spend this time on improving the fit between people's needs and the products and services that the company purchases. This project has priority and will be the first launched during e-business project phase 1 . 
At the beginning of the project, Drivindus observed a certain immaturity on the part of solution designers in terms of their knowledge of the Purchasing function. Specifically, there seemed to be a lack of awareness of what people expect in terms of procurement management and performance measurement. The company would like to develop certain functionalities leading to a standardisation of technical specifications, globalisation of purchases, development of framework contracts and above all, access to new reporting tools. Web catalogue solutions offer basic 'meta-catalogue' functions (or catalogue catalogues) that homogenise formats and offer comparisons of similar products offered by different suppliers. Drivindus would like to develop its marketplace in conjunction with a service provider who has a sufficiently open mind to be willing to listen to requests from the Project Manager - and whose vision of the Purchasing function is similar to the group's. This project will be launched in parallel with the online bidding project, i.e. during phase 1 of the e-business project.

The monitoring tool must be capable of measuring suppliers' service quality, viability, innovation potential, asset value and key competencies. As such, it will subject suppliers to a financial audit (financial solidity, cost structure, profitability, etc.), industrial audit (production capacities, equipment maintenance, staff training, etc.) and technological audit (R\&D investment, number of innovations over a given period of time, number of partnerships with lower tier suppliers, etc.). These criteria will be periodically analysed to determine which suppliers should be certified and feature on a short list - or blacklist - and monitored for future developments. Towards this end, there needs to be a supplier database replete with SAP codification and interfacing (since this is the integrated management package used throughout the Drivindus group). The project will complement the two preceding projects and will be launched at the end of period 1, before the beginning of period 2 .

Drivindus would like to design a highly strategic tool that is specific to the particular relationships it has developed with suppliers. Two applications will have to be designed and developed internally with the help of external providers, mainly consultants. The first is a tool for managing supplier quality incidents, one that should facilitate monitoring, improve problem-solving and keep malfunctions from recurring. The system should, for example, contain different alert levels requiring suppliers to act with various degrees of urgency. The second application shares the main performance indicators with those suppliers who have a more consolidated vision of their role as value creators working on Drivindus's behalf. The SRM project will be launched in 2008 , i.e. during phase 2 of the e-business project, at the same time as the Intranet platform.

\section{Presenting Solutions}

After testing several platforms, Drivindus signed in April 2006 a partnership with Freemarkets, a marketplace specialised in reverse auctions. The agreement covered the management of $\$ 300$ million worth of supplier deals for a period of two years. These purchases mainly involved capital equipment like electronic or mechanical components, chemical products or organic matter. Freemarkets seemed very willing to listen to Drivindus's wishes. The principle of electronic auctions is that participants can monitor the price action and adjust their own bids in real time. Drivindus is supposed to allocate contracts based on a supplier's overall performance, with price 
being only one aspect of the decision. Price competition only occurs after suppliers have been pre-selected for their ability to work to some very rigorous specifications. The goal is not only to save money but also to reduce and rationalise the company's shortlist of suppliers. If a firm already working with Drivindus takes part in an auction and wins the contract, it will have to satisfy the company's minimum product quality and service conditions.

Drivindus has also got together with IBM Business Consulting, chosen to serve as integrator of the Commerce One electronic catalogue solution. This is a software structure that standardises catalogues and customises them to fit different needs. Commerce One is not only able to define a standard but can also achieve a large enough critical mass in a sufficiently short period of time to recoup the costs incurred developing the solution. This also means that Commerce One has had some major financial problems and is in a weak bargaining position when dealing with customers. Drivindus has suggested to Commerce One then it invest in the latter company's solution. An opportunity arose for the group in 2007 in the form of an 'Escrow Agreement', i.e., a contract enabling it to obtain exclusive ownership of the core application's Java source code. Using this core, IBM Business Consulting can supplement existing functionalities with new ones specific to Drivindus. This allowed the company to design a customised solution after receiving advice from IBM experts - and to do this at the lowest possible cost, since it could start with a solution that already exists.

It was on the basis of a product specification determined by Drivindus's P3 Project Manager that the monitoring solution was developed to remedy the present lack of satisfactory solutions. Because the stakes are so high, Drivindus has invested in a single platform whose design has been subcontracted to a small software consultant before being passed on to Cap Gemini. This supplier referencing package has been built on a module-via-module basis, i.e., functionality-by-functionality, to enable a progressive installation and optimise the management of its particularly high investment costs. The customisation advantage is entirely realised by Drivindus, which has kept a close eye on the project all throughout, validating each step by rigorously applying its specifications before moving onto the following step. Drivindus does not hesitate to finance all of the developments needed to obtain certain functionalities that may be entirely specific to its line of business.

The first application of the SRM solution is a supplier quality incident management platform called IMS (Incident Management System) that is supposed to encourage, structure and accelerate the processing of any incidents. If one occurs, the quality manager records it on IMF and creates a file with photos and recordings done using measurement and control tools, before transmitting everything to the supplier involved. The supplier will then have very short period of time to respond, step-bystep, via a method called QRQC (Quick Response Quality Control):

- In fewer than 24 hours, the supplier will have to implement conservational actions, i.e. suggest an immediate action plan addressing any defects and preventing any new defective goods from reaching Drivindus.

- In fewer than five days, the supplier will have to provide analysis of the causes of the incident and explain why are the defect appeared and why it was not detected on the supplier's premises before Drivindus noticed it. The group's preference at this 
level is to get suppliers to act autonomously and take responsibility for their own quality and not leave this to Drivindus.

- After a further five days, the supplier must confirm that it has adopted an action plan aimed at avoiding any recurrence of the incident - and that is able to use statistical data and all necessary documentation to prove that the action plan will be both efficient and effective.

SRM is a very visual tool that ties KM relating specifically to the incidents in question to information shared with all of the divisions in the Drivindus group, thereby accelerating business or sectorial level problem-solving, even if the incident occurs in another division.

\section{Stages of Deployment}

This tool, which is very destabilising for both buyers and suppliers, has become standard. It is associated with a communications plan and also an intensive training programme for each buyer. Suppliers (especially French ones) continue to view this practice as abusive and anti-competitive, simply because it leaves them exposed to global competition. Other suppliers see it as an opportunity to increase their market share at Drivindus. As time goes by, the platform will be used by almost 800 of the 1,000 buyers who currently work with Freemarkets and manage all of the auction phases for which they are responsible. The buyers in question are mainly those working in branches like administrative costs, engineering, transportation and raw materials. All buyers receive training supervised by the 'key users' who have led the platform's testing and debugging process, with Freemarkets maintaining responsibility for preparing the auction. Subsequently, the buyers themselves will manage all of the stages and, once they start to master the tool, assume an advisory role. Within a few years, this solution will be used for nearly $20 \%$ of all purchasing volumes, or the equivalent of more than $€ 1$ billion. This amounts to a total cost reduction of between 9 and $12 \%$.

The idea here is to have a custom-made package that will be hosted internally, and not to use an external marketplace. The problems experienced with Commerce One ultimately became an opportunity for Drivindus, which after appropriating the core of their marketplace is now able to build its own tailor-made portal. The web catalogue solution was launched in 2006 and deployed on all sites worldwide from 2008 onwards. Catalogues were only used on $10 \%$ of all non-production-related purchasing at the time, but Drivindus does have the possibility of organising its calls for tender online and hopes to increase the overall percentage of work done in this way to $50 \%$ by the year 2010. Despite being highly supportive of the solution at first, buyers subsequently felt quite disappointed, if only because their early expectations were too high. This kind of marketplace is a victim of its own success, with technical limitations having bothered users to such an extent that a new version was installed in 2009 - since when users and suppliers alike have been very satisfied with its performance. The time needed to process a tender bid has been divided by a factor of three and internal customers' satisfaction levels have risen noticeably.

Performance monitoring has mainly focused on production-related purchases. This allows people to have a global and segmented vision of the purchases that Drivindus 
makes across the world, while tracking leading indicators like quality, cost and delays. Its extension to non-production-related purchasing will be organised over the course of 2009. When it was first set up, this tool was considered quite restrictive insofar as it needed to be systematically updated on a monthly basis. Over time however, it has become a key information source for managing suppliers. Its main weakness remains the reliability of the information it provides, which can be incomplete, redundant and even obsolete. There is still some room for improvement in the sense that users need to be more rigorous in updating the tool with whatever information they acquire.

After two months testing the Covisint solution - a specialist automotive sector electronic marketplace created by General Motors, Ford and Daimler Chrysler Drivindus was unconvinced by the experience and initiated the development of a dedicated solution. Contrary to the cumbersome nature, technical complexity and rigidity of Covisint - which has become increasingly difficult to implement Drivindus has been looking for a very simple and ergonomic solution requiring little training and featuring only functionalities that are strictly necessary. Of course, the upfront costs of designing this kind of collaborative platform were extremely expensive, but Drivindus's project manager has decided to devote a lot of time and energy to its relatively long functional design phase and remains intransigent. The initial functionalities were implemented very quickly in 2008 after the arrival of a new Quality Manager. This extranet tool has a very good reputation among buyers and suppliers alike. In turn, this has led to the implementation of a standardised quality incident resolution process, which has considerably facilitated and accelerated the resolution of any and all incidents.

\section{References}

1. Beukers, M., Versendaal, J., Batenburg, R., Brinkkemper, S.: The Procurement Alignment Framework: Construction and Application. Wirtschaftsinformatik 48(5) (2006)

2. Brousseau, E.: The Governance of Transaction by Commercial Intermediaries: an Analysis of the re-engineering of intermediation by electronic commerce. International Journal of the Economics of Business 9(3) (2002)

3. Carter, C.R., Ellram, L.M.: Thirty-five years of the Journal of Supply Chain Management: where have we been and where are we going? Journal of Supply Chain Management 39(1) (2003)

4. Cousins, P.D., Lawson, B., Squire, B.: An empirical taxonomy of purchasing functions. International Journal of Operations \& Production Management 26(7) (2006)

5. Davila, A., Gupta, M., Palmer, R.: Moving procurement systems to the Internet: The adoption and use of E-procurement technology models. European Management Journal 21(1) (2003)

6. Kaplan, S., Sawhnay, M.: E-Hubs: the new B2B Marketplaces. Harvard Business Review (May-June 2000)

7. Le, T., Rao, S., Truong, D.: Industry-Sponsored Marketplaces: a Platform for Supply Chain Integration or a Vehicle for Market Aggregation? Electronic Markets 14(4) (2004) 